\title{
Challenges of Mentoring in South African Construction Industry
}

\author{
*Clinton Aigbavboa, Ayodeji Oke, Madidimalo Mutshaeni \\ University of Johannesburg, Johannesburg, South Africa \\ *caigbavboa@uj.ac.za, emayok@gmail.com, Mutshaenimadid@gmail.com
}

\begin{abstract}
One of the major requirements in the development and growth of an industry or organisation is the incubation of new workforce through appropriate recruitment processes, proper training and effective mentoring by experienced members. However, the process is not expected to be smooth owing to individual dispositions and attitudes, organisation interest, and avenues and opportunities for mentoring, amongst others. In this study, various challenges of mentoring encountered by mentees and mentors were examined with a view to promoting effective mentoring among professionals in the construction industry in the quest to improve their productivity and thereby enhance better performance in construction projects. Data on professionals in the built environment were collected through the administration of questionnaires using a convenient sampling technique. Personality issues that are concerned with differences in behaviours and dispositions to matters are the major challenges of mentoring in the construction industry. More so, attitudes of the mentees dictate and affect behaviours of mentors, and vice-versa. In view of this, professionals involved in mentoring should be concerned about their attitudes to each other and personal beliefs should not be a basis for judgment. Mutual respect and concern for growth and development should form the basis of mentoring relationships.
\end{abstract}

Keywords: Knowledge, Mentee, Mentor, Skill, Training

\section{Introduction}

In relation to an increase in the demand for complex and innovative developments, Nkomo and Thwala (2014) noted that the construction industry has become highly competitive and the need for training and development of workmen and professionals cannot be over-emphasised. There are several ways of achieving this and one of them is through mentoring. According to Hoffmeister et al. (2011), the concept of mentoring is related to overseeing someone's career and personal development. Therefore, the purpose and objective of mentoring is to groom potential construction leaders for the purpose of their gaining the necessary experience, skills and emotional balance for better performance. This does not only empower the personnel but also promotes improved productivity of the organisation or industry. For this process to be effective and successful, the two parties involved, namely, mentor and mentee, must possess certain characteristics, attributes and understanding of mentoring and its techniques (Yokwana, 2015). However, Wong and Premkumar (2007) noted that mentoring has become ineffective owing to various challenges, and rarely practised as expected. The challenges faced in mentoring relationships, according to Nkomo and Thwala (2014) can become dysfunctional and eventually lead to overdependence, deception, resentment, or harassment. The mentoring relationship can also impact negatively in terms of fairness as the challenged may see it as a strategy to get ahead. Pinho et al. (2005) noted that this is mostly common with cross-gender and cross-race relationships.

Mentoring is supposed to be done with the intention of empowering young inexperienced employees who could possibly rise through the ranks to become future leaders in the construction industry. Even though mentors are supposed to be senior employees with years of experience, Nichols (2016) noted that years of experience and practice do not necessarily guarantee that any senior employee can automatically become a leader or mentor. Mentors should be individuals who have showed excellent leadership qualities in the company as they are supposed to inspire young inexperienced employees (Dionisio, 1994). Scandura et al. (1992) pointed out that the world of a mentor is completely unique and different in its own way, encompassing personal and professional motives that can only be known by the mentor. It was further noted that a mentor's intentions are never constant; they are subject to changes through time as a result of several factors. Effective mentoring has the potential to ensure continuity and enhance better development and overall growth of individuals and the organisation in general. In the construction industry, the process is vital for career development and growth of construction professionals and workforce engaged in delivering infrastructures. Yokwana (2015) noted that the ultimate goal of any mentoring relationship is to empower 
each other so it is important to maintain constant engagement, be aware of the purpose and be guided by essential principles. In this study, various challenges to effective mentoring are examined and the findings will be of importance to employees and employers in the built environment in the quest to ensure effective mentoring. This will lead to better productivity and thereby improved performance of construction projects.

\section{Literature Review}

Mentoring in the construction industry: According to Nkomo and Thwala (2014), the construction industry is extremely busy and its scope of work is usually complicated. It involves the use of heavy equipment and machinery as well as trained and experienced professionals with diverse skills and abilities. Thus, it is very different from typical everyday office jobs. Owing to its being a complex and highly competitive industry, it is important for effective mentoring to take place in order to develop, train and mould future leaders who could run and lead the industry. Mentoring was described by Amelink (2010) as being known to assist in career development. However, mentoring relationships sometimes fail to produce the desired results. Through the process of mentoring, Yokwana (2015) concluded that experienced and knowledgeable individuals referred to as mentors assist mentees, that is new or fresh professionals, in order to discover their potential and improve their productivity concerning their contribution to the engineering and built environment. Furthermore, , Russel (2006) observed that mentees are also shown how to use the theoretical knowledge they acquired at tertiary level and furthermore, are properly guided in defining, pursuing and achieving their career goals.

Hamlin and Sage (2011) suggested that the effectiveness of any mentoring relationship depends largely on the characteristics possessed by parties involved, that is, mentor and mentee, as well as on whether both parties know how to take advantage of the opportunities presented by the other party. The quality of the relationship between a mentor and a mentee is a key factor to ensuring successful mentoring. For effective mentoring relationships, mentors and leaders need to adopt both pulling and pushing mentoring styles (Nichols, 2016). This, according to Hamlin and Sage (2011), was described as presenting a safe avenue where the mentees feel able to share and express their agendas, interests and goals; a place where support is offered by listening; an opportunity to ask the right relevant questions, stimulating the mentee's thinking in such a way that they arrive at answers to their problems; as well as offering needed ideas, knowledge, tools and techniques that could enhance productive thinking and better performance.

According to Wong and Premkumar (2007), mentors can help to develop effective mentoring relationships by creating a safe environment; taking time to listen attentively without bias or passing unfair judgment; agreeing on objectives and goals rather than approaches; and acknowledging, accepting and appreciating differences when noticed. Stone (2007) highlighted the following characteristics of an excellent mentor in order for a mentoring relationship to be effective, namely strong interpersonal attributes; recognising the accomplishment of each other; being an excellent supervisor; accepting risks and uncertainties that are associated with mentoring; and willingness to be available to help in the advancement of individuals in an organisation. Hamlin and Sage (2011) included the following essential characteristics: active listening and asking questions; setting clear goals; flexibility; as well as building and maintaining close and harmonious relationships with management through trust, empowerment, focus and empathy.

The responsibility for effective mentoring relationships does not only lie with the mentor in providing the needed guidance and direction: the role of the mentee is also as important. Stone (2007) highlighted basic characteristics that an excellent mentee should possess in order to secure an effective mentoring relationship, and overcome basic challenges that may arrive. These include demonstrating intelligence, showing initiative and taking responsibility for own development. In addition, , Hamlin and Sage (2011) noted the following attributes: expressing needs clearly and helping to identify development goals; seeking input from the mentor; demonstrating commitment by following up on points set in meetings; making time to attend meetings punctually; maintaining confidentiality; and seeking to understand roles, responsibilities and boundaries. It is evident from previous studies that effective mentoring in any organisation or industry, including the construction industry, has many benefits if fully and effectively harnessed. Amelink (2010) noted that effective mentoring assists in developing mentees' careers as they are exposed to the practical aspect of their career by their mentor. While being close to a mentor, a mentee is able to associate with 
organisations that could possibly assist in career growth and future employment or partnerships. Positive career developments have been associated with mentoring as people who had been mentored effectively reported on how they had received career guidance and support, leading later to increased salaries and job satisfaction (Nkomo \& Thwala, 2014). This indicates that mentoring has a positive impact on an individual's growth and development.

\section{Methdology}

Owing to the nature of the variables to be examined, category of data to be collected and character of respondents involved, a survey design was adopted for this study. Using existing literature as the basis for obtaining information relating to general challenges to effective and efficient mentoring in industries and organisations, a quantitative research approach was adopted for data collection. Close-ended questionnaires with multiple-choice answers were adopted as research instruments and they were administered on construction professionals practising in the Gauteng region of South Africa using convenience sampling. These professionals are architects, quantity surveyors, engineers, construction managers and construction project managers. In designing the instrument, it was ensured that negative, irrelevant, biased and long questions were avoided. The first section of the instrument was used to collect the biographical information of the respondents while the second part was framed to relate directly with the objective of the study. The five--point Likert scale was employed where $1=$ Strongly disagree (SD); $2=$ Disagree (D); $3=$ Neutral (N); $4=$ Agree (A); and 5= Strongly agree (SA). Mean item scores (MIS) and standard deviations (SD) were computed from the scale using the Statistical Package for Social Science (SPSS) and the results were used to assess the order of importance of the identified factors. Using Cronbach's alpha value, reliability tests were conducted on the two sections in the second part of the instrument, which are challenges from the perspectives of mentees and problems caused by mentors in a mentoring relationship. The analysis revealed values of 0.773 and 0.716 respectively. These are greater than the acceptable reliability coefficient of 0.70 (Santos, 1999), therefore it could be concluded that the instrument adopted for the study is reliable.

\section{Findings and Discussion}

Forty-five questionnaires were distributed, thirty-eight were retrieved while thirty-four were adequately completed and found suitable for further analysis. There were 55.9 per cent and 44 per cent of male and female respondents respectively, indicating gender balance and adequate representation. The age groups of these professionals indicated that 64.7 per cent are between 20 and 25years, 29.4 per cent are between 26 and 30 years while 5.9 per cent are 31 years and older. Considering respondents' years of experience and practice in the construction industry, both groups of mentees and mentors were captured. About 55.3 per cent, 23.7 per cent, 13.3 per cent and 7.8 per cent have 1 to 10,11 to 20,21 to 30 and above 30 years of experience respectively. Respondents are also spread across various professions in the industry. These include architecture, engineering, construction management, and quantity surveying and construction project management. Of these, 62.1 per cent are junior employees while 35.9 per cent are senior employees and they have been involved in about 11 projects on the average.

The basic challenges affecting mentoring relationships in the construction industry were examined in this study. Table 1 displays the challenges of mentoring from the perspective of mentees. Judging by the five-point Likert scale, the highest MIS value of the identified challenges is 2.42 which is less than the average of the scale. However, the results were ranked as follows: 'My mentor and I had different personalities' was ranked first and had a mean score of 2.42 and SD=1.640; 'My mentor and I' argued was ranked second with a mean score of 1.73 and $\mathrm{SD}=0.977$; 'My mentor's personal problems affected work' was ranked third with a mean score of 1.70 and $\mathrm{SD}=1.104$; 'My mentor had multiple personalities which made it difficult to work together' was ranked fourth with a mean score of 1.55 and $\mathrm{SD}=1.063$; and 'My mentor was self-absorbed' was ranked fifth with a mean score of 1.48 and $\mathrm{SD}=0.755$. In addition, 'My mentor was distant towards me' was also ranked fifth with a mean score of 1.48 and $\mathrm{SD}=0.939$; 'My mentor delegated duties inappropriately' was ranked sixth with a mean score of 1.36 and $\mathrm{SD}=0.549$; 'My mentor took credit for the work that was not his/her own' was ranked seventh and had a mean score of 1.33 and SD=0.777; 'My mentor's attitude was bad and negative' was ranked eighth with a mean score of 1.30 and $\mathrm{SD}=0.684$; 'My mentor excluded me from projects intentionally' was ranked ninth with a mean score of 1.27 and $\mathrm{SD}=0.517$; and 'My efforts were 
sabotaged' was ranked tenth with a mean score of 1.21 and $S D=0.650$. Aligned to these findings, Nkomo and Thwala (2014) stated that the construction industry has tight deadlines that can cause tension and anxiety, making it difficult to work together with mentees. Furthermore, Rogers (2008) noted that personality conflicts can pose as the most difficult challenge to deal with, followed by constant arguing and personal problems affecting work. However, Starr-Glass (2014) believed that the main challenge would be when a mentor starts talking to the mentee as if the later works for the former, which in turn brings about a bad attitude from the mentees side.

\section{Table 1: Mentee challenges}

\begin{tabular}{llll}
\hline & MIS & SD & Rank \\
\hline My mentor and I had different personalities & 2.42 & 1.64 & 1 \\
My mentor and I argued & 1.73 & 0.98 & 2 \\
My mentor's personal problems affected work & 1.70 & 1.10 & 3 \\
My mentor had multiple personalities which made it difficult to work together & 1.55 & 1.06 & 4 \\
My mentor was self-absorbed & 1.48 & 0.76 & 5 \\
My mentor was distant towards me & 1.48 & 0.94 & 5 \\
My mentor delegated duties inappropriately & 1.36 & 0.55 & 6 \\
My mentor took credit for work that was not his/her own & 1.33 & 0.78 & 7 \\
My mentor's attitude was bad and negative & 1.30 & 0.68 & 8 \\
My mentor excluded me from projects intentionally & 1.27 & 0.52 & 9 \\
My efforts were sabotaged & 1.21 & 0.65 & 10 \\
\hline
\end{tabular}

Table 2 highlights the results of the challenges mentors experienced with mentees during their mentoring relationships. The results indicate that the major challenge is related to the fact that mentees always want to prove themselves which may not go down well with their mentors. This is ranked first with a mean score of 4.03 and $\mathrm{SD}=1.314$. Other factors were ranked as follows: 'I took more work than I could handle' was ranked second with a mean score of 2.65 and $\mathrm{SD}=1.412$; and 'My ambition got in the way' was ranked third with a mean score of 2.38 and $\mathrm{SD}=1.280$. Furthermore, 'My mentor gave me tight deadlines I could not meet' was ranked fourth with a mean score of 2.29 and $\mathrm{SD}=1.338$ and 'I became over-dependent on my mentor' was ranked fifth with a mean score of 1.71 and $S D=1.088$. In support of the findings, Pinho et al. (2005) stated that mentees may overwork themselves just to prove themselves. Yet another challenge occurs when mentors take control and mentees end up being dependent on the mentor. It was further pointed that a mentoring relationship may lead to over-dependence, resentment, deception or harassment. Starr-Glass (2014) also advised that mentees should not change the focus of their role in the course of trying to prove themselves to their mentor or leader. However, Rogers (2008) concluded that regardless of the mentoring relationships nature, becoming over-dependent on a mentor is a major trap that should be avoided.

Table 2: Mentor challenges

\begin{tabular}{llll}
\hline & MIS & SD & Rank \\
\hline I wanted to prove myself & 4.03 & 1.31 & 1 \\
I took more work than I could handle & 2.65 & 1.41 & 2 \\
My ambition got in the way & 2.38 & 1.28 & 3 \\
My mentor gave me tight deadlines I could not meet & 2.29 & 1.34 & 4 \\
I became over dependent on my mentor & 1.71 & 1.09 & 5 \\
\hline
\end{tabular}

\section{Conclusion and Recommendation}

The challenges associated with mentoring are enormous but surmountable. Aside from the individual differences of the two major parties, namely, mentee and their mentor, there are external factors that impact mentoring both positively and negatively. The external factor can be a third party intervention whereby someone who is not a major party to the relationship influences either or both parties and thereby affects the relationship. There can also be environmental factors such as economic issues, and the organisation's beliefs and practices, among others. The major challenges of mentoring are related to time management, a lack of or ineffectual meetings, a lack of expressed interest by top management, mentee and mentors' clash of personalities, mentees' trying to prove themselves, mentees' taking more work than they can handle and 
mentees' ambition getting in the way. However, a good mentor should be willing to sacrifice time for the mentee but care should be taken so that the mentee does not become too dependent on the mentor. Mentors and mentees should never be forced into mentoring relationships: they should be allowed to develop over time. It also necessary for mentors and mentees to communicate and highlight their basic objectives and work towards the same goal. When the mentor is at fault, it is important to revisit the positive intentions for mentoring. Sometimes mentors may become discouraged because of a lack of visible results, simply because they are not aware of how the mentees are benefitting from their partnership. This is because much of the value added to a mentee, in terms of self-confidence, self-esteem and trust, are not visible or tangible. Furthermore, , when the mentee is at fault, discussion with the mentor should take place to resolve issues and strengthen the relationship so as to refocus on unified agenda and goals. It is also necessary for managers and directors of construction and consulting firms in the construction industry to establish a framework and conducive environment for effective mentoring. This will not only benefit the firms but the general performance of the industry.

\section{References}

Amelink, C. T. (2010). Mentoring and women in engineering (An ARP Literature Overview). Research on women in science and engineering. Online at https://www.engr.psu.edu/awe/ Accessed on 7 August 2016.

Dionisio, J. M. (1994). Mentoring for consulting engineers. Journal of Management in Engineering, 10(5), 1619.

Hamlin, R. G. \& Sage, L. (2011). Behavioral criteria of perceived mentoring effectiveness: An empirical study of effective and ineffective mentor and mentee behavior within formal mentoring relationships. Journal of European Industrial Training, 35(8), 752-778.

Hoffmeister, K., Cigularov, K. P., Sampson, J., Rosecrance, J. C. \& Chen, P. Y. (2011). A perspective on effective mentoring in the construction industry. Leadership \& Organization Development Journal, 32(7), 673688.

Nichols, A. L. (2016). What do people desire in their leaders? The effect of leadership experience on desired leadership traits. Leadership \& Organization Development Journal, 37(5), 658 - 671.

Nkomo, M. W. \& Thwala, W. D. (2014). Review of the importance of mentoring young graduates in the construction sector in South Africa, in Nkum R.K., Nani G., Atepor, L., Oppong, R.A., Awere E. and Bamfo-Agyei, E. (2014) (Eds.), Proceedings of the 3rd Applied Research Conference in Africa (ARCA) Conference, Accra Ghana, pp. 531-539.

Pinho, S. D., Coetzee, M. \& Schreuder, D. (2005). Formal mentoring: Mentee and mentor expectations and perceived challenges. SA Journal of Human Resource Management, 3(3), 20-26.

Rogers, M. (2008). Coaching, counselling, and mentoring: How to choose and use the right technique to boost employee performance. Career planning and Ault Development Journal, 24(1), 247-259.

Russell, J. S. (2006). Mentoring in Engineering. Leadership and Management in Engineering, 6(1), 34-37.

Santos, J. R. A. (1999). Cronbach's alpha: A tool for assessing the reliability of scales. Journal of Extension, 37(2), 1-5.

Scandura, T. A., Tejeda, M. J., Werther, W. B. \& Lankau, M. J. (1996). Perspectives on mentoring. Leadership \& Organization Development Journal, 17(3), 50-56.

Starr-Glass, D. (2014). Three degrees of separation: Strategies for mentoring distanced transnational learners. Online tutor. Online at http://www.igi-global.com/chapter/ Accessed on 7 August 2016.

Stone, P. (2007). Opting out? Why women really quit careers and head home. Journal of Family Communication, 9(2), 131-133

Wong, A. T. \& Premkumar, K (2007). An introduction to mentoring principles, processes and strategies for facilitating mentoring relationships at a distance. Online at http://www.usask.ca/gmcte/Accessed on 15 September2015.

Yokwana, N. R. (2015). Factors contributing to the successful mentorship of women in the South African construction industry. Master's thesis, Cape Peninsula University of Technology, South Africa. 